\title{
Extending Consumer Categorization Based on Innovativeness: Intentions and Technology Clusters in Consumer Electronics
}

\author{
Frank J. van Rijnsoever \\ Innovation Studies, Copernicus Institute of Sustainable Development, Utrecht University, P.O. Box 80115, \\ 3508 TC Utrecht, The Netherlands. E-mail: f.vanrijnsoever@geo.uu.nl \\ Carolina Castaldi \\ School of Innovation Sciences, Eindhoven University of Technology, P.O. Box 513, 5600 MB Eindhoven, \\ The Netherlands. E-mail: c.castaldi@tue.nl
}

\begin{abstract}
Consumer categorizations based on innovativeness were originally proposed by E.M. Rogers (2003) and remain of relevance for predicting purchasing behavior in high-tech domains such as consumer electronics. We extend such innovativeness-based categorizations in two directions: We first take into account the existence of technology clusters within product domains and then enrich the definition of consumer innovativeness by considering not only past adoption behavior but also future purchase intentions. We derive a novel consumer categorization based on data from a sample of 2,094 Dutch consumers for the case of consumer electronics. In so doing, we apply endogenous categorization techniques that represent a methodological improvement with respect to previously applied techniques.
\end{abstract}

\section{Introduction}

The goal of segmented marketing is to specify homogenous categories of consumers from a heterogeneous population (Morwitz \& Schmittlein, 1992). Ideally, the categories help to more accurately predict future purchase behavior and thus allow more effective marketing strategies. Typical characteristics upon which to base segmentation are sociodemographics, attitudes, intentions, and behavior (Blackwell, Miniard, \& Engel, 2001; Morwitz \& Schmittlein, 1992). At the same time, a popular approach to classify consumers in innovation studies is to characterize them based on actualized innovativeness, or "the degree to which an individual or other unit of adoption is relatively earlier in adopting new ideas than other members of a social system" (Rogers, 2003, p. 280).

Received October 9, 2010; revised February 16, 2011; accepted April 14, 2011

(C) 2011 ASIS\&T • Published online 16 May 2011 in Wiley Online Library (wileyonlinelibrary.com). DOI: 10.1002/asi.21567
Rogers (2003) distinguished five categories: innovators, early adopters, early majority, late majority, and laggards. To each category, a set of characteristics was attributed. While this categorization has proved useful to map adopter types, several authors have found that actualized innovativeness is a poor predictor of future purchasing (Goldsmith \& Hofacker, 1991; Hoffmann \& Soyez, 2010). In this article, we aim to extend the use of actualized innovativeness as a base for segmented marketing. The relevance of this analysis is particularly strong in high-tech product domains where product life cycles are increasingly short and where the survival of a company may crucially depend on early adopters acting as opinion leaders and determining the success of new products (Hoffmann \& Soyez, 2010). Consumer electronics is one such product domain and will be the focus of our empirical analysis.

We propose two main extensions to current methodologies of actualized innovativeness-based consumer categorization. A first issue relates to the definition and measurement of actualized innovativeness. Innovativeness in general can be measured for a single idea (e.g., a product) or for a set of ideas (e.g., a product domain), the latter being the higher level of abstraction (Goldsmith, Freiden, \& Eastman, 1995; Midgley \& Dowling, 1978; Roehrich, 2004; Van Rijnsoever \& Donders, 2009). The main advantage of defining it at a higher level of abstraction is that the construct becomes more broadly applicable. For example, many predictors for innovativeness are usually either framed as product domain specific (e.g., opinion leadership: Flynn, Goldsmith, \& Eastman, 1996; involvement: Mittal \& Lee, 1989) or even as a personality trait (e.g., dispositional innovativeness: Midgley \& Dowling, 1978) or as general attitudinal measures (e.g., environmentalism: Dunlap, Van Liere, Mertig, \& Jones, 2000). In all such cases, one finds high 
correlations between the predictors and actualized innovativeness measured at the product-domain level. The other side of the coin is that the predictive validity at the level of productspecific adoption behavior is sacrificed (Ajzen, 2005; Goldsmith et al., 1995).

A further limitation of the cited studies is that all products in a single product domain are treated as equal and interchangeable, which does ill justice to the individual differences among the products. Past studies have shown that high-tech products might depend on each other in terms of functionality: This influences the sequence in which these products are adopted (Van Rijnsoever \& Castaldi, 2009) and whether they are adopted in combination with each other (Larose \& Hoag, 1996). This phenomenon is called technology clustering (see Rogers, 2003) and is particularly evident in the case of consumer electronics. Furthermore, evidence exists that the predictive validity of actualized innovativeness for future purchases is quite high in the case of multiple succeeding-technology generations (Van Rijnsoever \& Oppewal, 2009). This again is evidence that individual product differences need to be taken into account. Given these issues, we propose that actualized innovativeness can be defined at the product-domain level when used for segmented marketing, but attention should be given to the identification of technology clusters to preserve adoption predictability at the product level.

A second way to further improve the validity of actualized innovativeness is to not only look at past adoption behavior but also to include intentions for future purchase behavior. Many studies have tested the relationship between purchase intention and purchase behavior (e.g., Alexander, Lynch, \& Wang, 2008; Sheppard, Hartwick, \& Warshaw, 1988; Taylor, 1995). A well-known result is that intentions are not always translated into corresponding behavior (Ajzen, 2005), and are thus by no means a perfect predictor. Still, purchase intentions do bear a strong relationship with future behavior (Morwitz \& Schmittlein, 1992). We propose that in combination with actualized innovativeness, intentions can be used to design a more elaborate construct that describes current and future adoption behavior.

The aim of this article is to empirically explore categories of consumers on a domain-specific level, based on past adoption behavior and future purchase intentions, taking into account the underlying technology clustering. This article contributes to marketing practice by offering a relatively simple approach to identify segments of consumers based on their past behavior and intended future behavior.

In the following section, the data and methods are described: We use clustering techniques, allowing to take into account the broad set of variables in which we are interested. Further, we characterize the identified categories using several variables commonly associated with actualized innovativeness (e.g., Rogers 2003): opinion leadership (Flynn et al., 1996; Rogers \& Cartano, 1962), trendiness (Van Rijnsoever \& Donders, 2009), the information sources used to obtain ideas for adopting new innovations (Katz \& Lazarsfeld, 1964; Vishwanath, 2005), and also consumers'
TABLE 1. Descriptive statistics of sociodemographics compared to the Dutch population (data from CBS, 2007).

\begin{tabular}{lll}
\hline & \multicolumn{1}{c}{ Sample $M$} & Population $M$ \\
\hline Age & 44.3 years & 45.8 years \\
Gender & $50.0 \%$ male $(1,046)$ & $49.0 \%$ male \\
& $50.0 \%$ female $(1,048)$ & $51.0 \%$ female \\
$\begin{array}{l}\text { Education level } \\
\begin{array}{l}\text { (on a 5-point } \\
\text { education level scale) }\end{array}\end{array}$ & 2.91 \\
$\begin{array}{l}\text { No. of inhabitants } \\
\text { (on a 4-point ordinal scale) }\end{array}$ & $\begin{array}{l}50,000-10,000 \\
\text { inhabitants }(M d n)\end{array}$ & $\begin{array}{l}50,000-10,000 \\
\text { inhabitants }(M d n)\end{array}$ \\
\hline
\end{tabular}

sociodemographic characteristics. The last section discusses our results and highlights their implications.

\section{Research Design}

\section{Sample}

A survey among Dutch consumers was administered over a 3-week time span in December 2006. Respondents were approached in public places across The Netherlands and asked to fill out a questionnaire. They were told that they could win 20 Euros for participating. Filling out the questionnaire took about $10 \mathrm{~min}$. Quota by age groups and gender were used to ensure a representative sample of the Dutch population. The final sample consisted of 2,094 consumers varying in age between 16 and 88 years. Due to the quota, the sample turned out to be a good representation of the Dutch population in terms of age and gender, when compared to official government statistics (CBS, 2007). There was an overrepresentation of highly educated respondents: On a 5-point education-level scale (using a Dutch education system scale from 1 [no education finished] to 5 [finished university]): sample mean $=3.26$, population mean $=2.91$ (CBS, 2007). A sociodemographic comparison with population statistics is given in Table 1 . Of the data, $0.46 \%$ was a missing value. We dealt with the missing values by using multiple imputation (Donders, van der Heijden, Stijnen, \& Moons, 2006) with the PRELIS program (Jöreskog \& Sörbom, 2006), resulting in 2,067 usable cases (Twenty-seven cases were not imputed.)

\section{Measurement}

The written questionnaire asked respondents to indicate whether they owned one of 15 consumer electronic products ${ }^{1}$ (see Table 2) or wanted to own the product. All questions were asked in the following form:

I own a [one of the 15 products]

$\mathrm{O}-\mathrm{No}$, and I do not intend to purchase this product.

\footnotetext{
${ }^{1}$ The list provides a fair representation of the consumer electronic products available in the market at the time of the survey. They also span different phases in the product life cycle, as demonstrated by the different diffusion rates (Table 2). Standard television was not included in the empirical analysis since $98 \%$ of the Dutch households own one (CBS, 2007).
} 
TABLE 2. Descriptive statistics of ownership and purchase intention given in percentages $(N=2,067)$.

\begin{tabular}{|c|c|c|c|c|}
\hline & $\begin{array}{c}\text { No, no } \\
\text { intention }(\%)\end{array}$ & $\begin{array}{l}\text { No, but intends } \\
\text { to purchase }(\%)\end{array}$ & $\begin{array}{c}\text { First } \\
\text { purchase }(\%)\end{array}$ & $\begin{array}{l}\text { Replacement } \\
\text { purchase (\%) }\end{array}$ \\
\hline Mobile phone & 7.7 & 1.6 & 19.9 & 70.8 \\
\hline DVD player & 15.1 & 6.2 & 48.8 & 29.9 \\
\hline Broadband Internet & 20.3 & 5.6 & 45.9 & 28.3 \\
\hline Desktop & 20.9 & 3.6 & 17.8 & 57.6 \\
\hline Digital camera & 27.6 & 13.4 & 39.1 & 19.8 \\
\hline Mobile telephone with camera function & 44.2 & 7.5 & 23.7 & 24.7 \\
\hline Dolby surround system & 47.4 & 14.0 & 27.5 & 11.2 \\
\hline Notebook or laptop & 50.8 & 13.9 & 22.2 & 13.1 \\
\hline Flat-panel TV & 53.4 & 27.2 & 16.2 & 3.3 \\
\hline MP3 player & 60.2 & 5.7 & 21.7 & 12.4 \\
\hline Webcam & 63.2 & 5.2 & 23.4 & 8.2 \\
\hline High-definition TV (HDTV) & 69.0 & 19.6 & 9.0 & 2.4 \\
\hline iPod & 72.1 & 10.2 & 14.2 & 3.5 \\
\hline Game console & 73.8 & 3.1 & 10.6 & 12.4 \\
\hline Personal digital assistant & 81.4 & 7.3 & 7.9 & 3.5 \\
\hline
\end{tabular}

$\mathrm{O}$ - No, but I do intend to purchase this product for sure.

$\mathrm{O}-$ Yes, this is the first time I owned this product.

$\mathrm{O}-$ Yes, this is a replacement purchase.

Table 2 provides descriptive statistics of the ownership and intention variable for all products.

Actualized innovativeness is often measured as the number of products owned within a given product domain (Goldsmith et al., 1995; Midgley \& Dowling, 1978; Roehrich, 2004). Therefore, from the 15 questionnaire items, an actualized innovativeness measure was constructed by summing the total number of products owned. Total number of intended purchases is the sum of products that consumers intended to purchase. Total number of replacement purchases is the sum of the replacement purchases.

Trendiness captured the degree to which the respondent was involved in trends in the domain of consumer electronics. It was measured using a 5-point Likert scale, ranging from 1 (strongly disagree) to 5 (strongly agree), with questions used by Van Rijnsoever and Donders (2009); Cronbach's $\alpha$ was 0.87 .

Opinion leadership is defined as the degree to which an individual exerts an unequal amount of influence on the decisions of others (Robertson, 1971; Rogers \& Cartano, 1962). This was measured using the six-item, 5-point scale, ranging from 1 (strongly disagree) to 5 (strongly agree), by Flynn et al. (1996); Cronbach's $\alpha$ was 0.80.

To minimize the risk of common method bias (Podsakoff, MacKenzie, Lee, \& Podsakoff, 2003), the questions that measured trendiness and opinion leadership were posed prior to the ones that measured ownership. Indicators for these constructs were taken together by saving the regressed factor scores of a principle component analysis. This reduces measurement error and standardizes the scales, making them comparable.

We also measured consumers' use of information sources for idea generation: Consumers can tap into several information sources to obtain ideas for adopting new consumer electronics. Many studies measure information search by the actual time spent on the search activity, which is an objective measure. Still, measuring search time can be very problematic because consumers are asked in retrospect the exact amount of time spent. This is even more the case for gathering ideas, when the actual start time may be difficult to recall. Therefore, we chose a series of 5-point scale, ranging from 1 (strongly disagree) to 5 (strongly agree), indicators related to the different information sources used to find ideas about consumer electronics. We inquired about the use of five different types of sources, derived from Kiel and Layton (1981), and updated with Internet use: (1) internal search (own experience), (2) interpersonal channels, (3) mass media, (4) the world wide web (WWW), and (5) retailers. To further minimize the chance of common method bias, these indicators were included in a separate section of the questionnaire. Again, items were taken together by saving the regressed factor scores of the latent construct. Table 3 reports the full operationalization of the use of information sources together with the descriptive statistics.

We measured sociodemographic variables that have been previously associated with adoption behavior of consumer electronics (Leung \& Wei, 1999; Van Rijnsoever \& Donders, 2009; Vishwanath \& Goldhaber, 2003): age (in years), gender $($ male $=1$, female $=2)$, socioeconomic status (mean of education level and, if applicable, job level), and amount of inhabitants in the town of residence (using a 4-point scale, ranging from $1[0-10,000$ inhabitants $]$ to 4 [>100,000]).

\section{Data Analysis}

Rogers (2003) defined adopter categories by grouping consumers based on the number of standard deviations away from the mean actualized innovativeness, which is assumed to be a normally distributed variable. This method implies a rather arbitrary distinction between the groups. Instead, we aim at endogenously determining categories from the observed data. In additional, we define groups based on more variables than just actualized innovativeness. All four items of the 15 product ownership and intention variables are included 
TABLE 3. Measurement and descriptive statistics of use of information sources.

\begin{tabular}{llll}
\hline Variable & \multicolumn{1}{c}{ Measurement } & $M(S D) ;$ Factor loading \\
\hline Use of information sources & I find ideas to purchase new consumer electronics from: & & \\
& $\quad$ (using a 5-point Likert scale) & $3.28(1.08) ; 1.00$ & Own experience \\
& 1. My own experience & $3.07(1.18) ; 0.80$ & Interpersonal channels \\
& 2. Family living in my household & $3.38(1.00) ; 0.80$ & \\
3. Friends and relatives & $2.80(1.07) ; 0.87$ & Mass media \\
& 4. Radio and television & $2.94(1.09) ; 0.87$ & \\
5. Advertisements and folders & $2.65(1.22) ; 1.00$ & World Wide Web \\
& 6. Internet sites (no e-mail and chatting) & $3.00(1.07) ; 1.00$ & Retailers \\
\hline
\end{tabular}

in the clustering procedure. Endogenous categorization of consumers based on product-ownership, purchase-intention, and replacement-purchase variables also allows identifying the products that are owned in combination with each other, capturing the existence of technology clusters.

Given the need for an endogenous and multivariate clustering method, we identify categories using a latent class model with performance based on maximum likelihood estimation. Latent class models are preferred over traditional clustering methods such as hierarchical cluster or $k$-means clustering because they are more flexible with regard to distributions and scaling and measurement levels of observed variables and have less arbitrary clustering criteria (see Fraley \& Raftery, 1998; Vermunt \& Magidson, 2002). Other simulations also have shown that latent class models perform better at distinguishing underlying classes than two-step cluster procedures such as the one available in SPSS (Bacher, Wenzig, \& Vogler, 2004). Since our variables are measured on a nominal scale, a polytomous latent class model was fitted; this is a modelbased cluster technique specifically designed for categorical variables. An optimal cluster solution between one and eight categories was explored using the poLCA package (Linzer \& Lewis, 2010) of the R-program (R Development Core Team, 2007). The poLCA package is based on the expectationmaximization algorithm, which entails the risk of getting trapped in a local log likelihood minimum, instead of a global minimum (Haughton, Legrand, \& Woolford, 2009; Linzer \& Lewis, 2010). To counter this problem, for each cluster solution, the model was replicated 200 times. The Bayesian information criterion was used to determine the optimal cluster solution. Since the order of the categories produced is random, they were ordered afterwards by the actualized innovativeness.

Using a chi-square test, we explored how the segments produced by the optimal solution differed with respect to the categories of the 15 variables. Further, using analysis of variance (ANOVA), differences were explored with regard to actualized innovativeness, trendiness, opinion leadership, use of information sources, and sociodemographics (Gender and amount of inhabitants were assessed using a chi-square test.) Finally, we tested the degree to which these characteristics helped to predict group membership using a multinomial logit model, to check whether the information regarding combined product ownership (e.g., technology clustering) and purchase intention was not already captured in the other variables. Group membership was the dependent variable and trendiness, opinion leadership, use of information sources, and sociodemographics were independent variables.

\section{Results}

A five-category solution proved to be the optimal cluster solution. Group size varied between 14 and $24.1 \%$ of the sample. An ANOVA $(d f=4)$ revealed significant differences between the groups on all four variables. Figure 1 displays the five categories and how they scored on actualized innovativeness, $F=1048.59, p<0.001$, total number of intended purchases, $F=294.04, p<0.001$, total number of first purchases, $F=184.13, p<0.001$, and total number of replacement purchases, $F=1150.94, p<0.001$. The Appendix shows the product-specific distribution of the variables over the five groups. Chi-square tests revealed highly significant differences $(p<0.001)$ among the groups for all products.

The categories identified are qualitatively different from those in Rogers (2003) since they capture information about multiple variables related to actualized innovativeness; therefore, we propose distinctive new labels:

- The first category is heavy domain adopters and represents $20.6 \%$ of the sample. This category is characterized by a high degree of ownership for all products. Further, many products are a replacement purchase, indicating that this category has a need to stay up to date with existing functionalities. Purchase intentions are quite low in this category because the list of products in the survey only included products that were available on the market. Respondents already have followed up on their purchase intention by actual purchase behavior. If the set would have been expanded with products that were not on the market but expected shortly, purchase intentions would have probably been higher (discussed later).

- The second category represents second movers and consists of $16.8 \%$ of all respondents. This category is characterized by ownership of fewer products than for those of the heavy domain adopters and less replacement purchases, but the members of this category have the highest intention of purchasing the products they did not already own.

- The third and fourth categories are both cluster adopters. Both categories (24.3 and $24.2 \%$, respectively) have a relatively high degree of technology ownership; however, instead of 


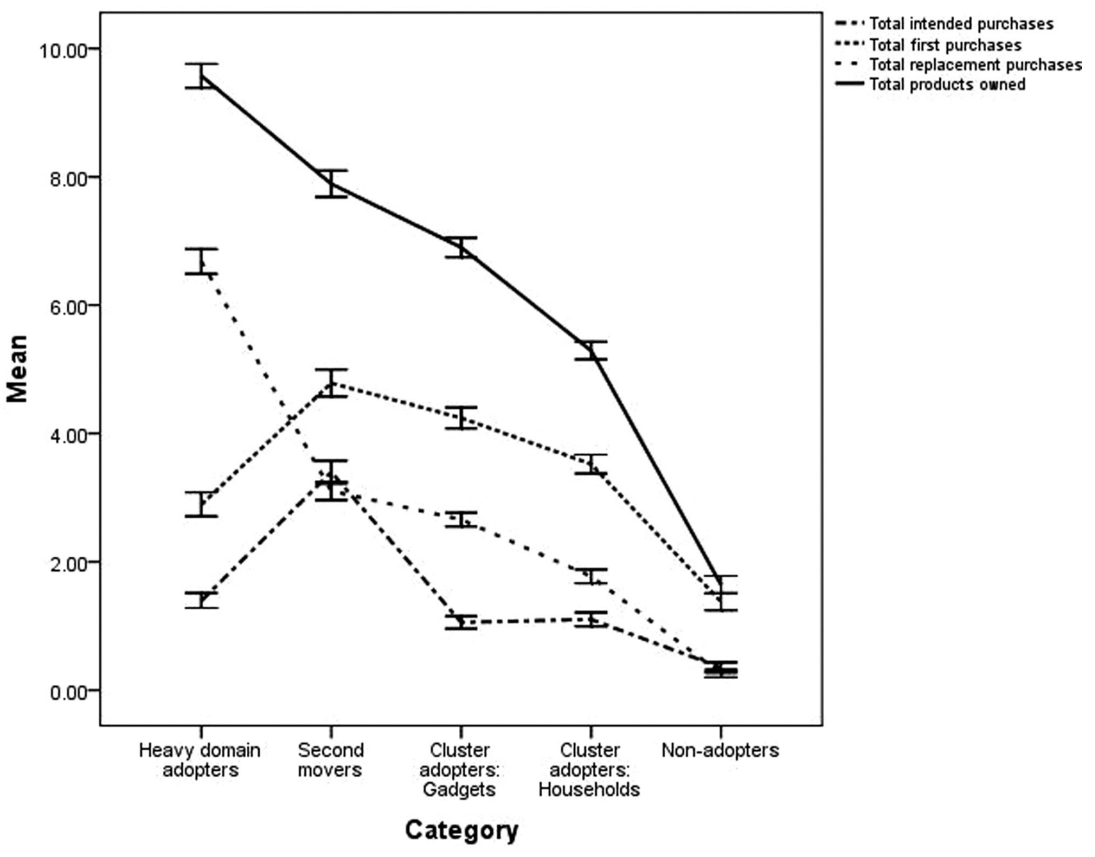

FIG. 1. Mean values and $95 \%$ confidence intervals per category for total intended purchases, total first purchases, total replacement purchases, and total products owned.

TABLE 4. Means of all variables over the categories.

\begin{tabular}{|c|c|c|c|c|c|c|c|c|c|c|}
\hline \multirow[b]{2}{*}{ Category no. } & \multicolumn{2}{|c|}{$\begin{array}{l}\text { Heavy domain } \\
\text { adopters } \\
426\end{array}$} & \multicolumn{2}{|c|}{$\begin{array}{c}\text { Second movers } \\
348\end{array}$} & \multicolumn{2}{|c|}{$\begin{array}{l}\text { Cluster adopters: } \\
\text { Gadgets } \\
502\end{array}$} & \multicolumn{2}{|c|}{$\begin{array}{l}\text { Cluster adopters: } \\
\text { Households } \\
501\end{array}$} & \multicolumn{2}{|c|}{$\begin{array}{l}\text { Nonadopters } \\
290\end{array}$} \\
\hline & $M$ & $S D$ & $M$ & $S D$ & $M$ & $S D$ & $M$ & $S D$ & $M$ & $S D$ \\
\hline Total products owned & 9.57 & 1.94 & 7.89 & 1.94 & 6.90 & 1.73 & 5.29 & 1.58 & 1.64 & 1.20 \\
\hline Total intended purchases & 1.40 & 1.22 & 3.40 & 1.69 & 1.06 & 1.10 & 1.11 & 1.25 & 0.37 & 0.73 \\
\hline Total first purchases & 2.89 & 1.96 & 4.78 & 1.99 & 4.24 & 1.84 & 3.52 & 1.67 & 1.38 & 1.14 \\
\hline Total second purchases & 6.68 & 2.03 & 3.10 & 1.35 & 2.66 & 1.21 & 1.77 & 1.22 & 0.26 & 0.51 \\
\hline Trendiness $(M=0)$ & 0.61 & 0.94 & 0.42 & 0.88 & 0.03 & 0.88 & -0.34 & 0.83 & -0.88 & 0.78 \\
\hline Opinion Leadership $(M=0)$ & 0.51 & 0.96 & 0.28 & 0.94 & 0.06 & 0.92 & -0.28 & 0.88 & -0.70 & 0.89 \\
\hline Own experience $(M=0)$ & 0.30 & 0.86 & 0.16 & 0.92 & 0.07 & 0.92 & -0.14 & 1.00 & -0.53 & 1.16 \\
\hline Interpersonal sources $(M=0)$ & 0.01 & 0.98 & 0.06 & 0.92 & 0.10 & 0.92 & 0.04 & 1.04 & -0.34 & 1.13 \\
\hline Mass media $(M=0)$ & 0.11 & 0.97 & 0.23 & 0.90 & 0.08 & 0.97 & -0.11 & 1.00 & -0.38 & 1.08 \\
\hline World Wide Web $(M=0)$ & 0.50 & 0.91 & 0.30 & 0.94 & 0.19 & 0.90 & -0.27 & 0.90 & -0.95 & 0.71 \\
\hline Retailers $(M=0)$ & 0.17 & 0.94 & 0.22 & 0.90 & -0.01 & 0.94 & -0.12 & 1.03 & -0.31 & 1.15 \\
\hline Age (years) & 36.72 & 14.16 & 35.09 & 15.28 & 31.68 & 15.53 & 50.83 & 13.45 & 67.69 & 13.18 \\
\hline Gender (\%female) & \multicolumn{2}{|c|}{31.5} & \multicolumn{2}{|c|}{41.1} & \multicolumn{2}{|c|}{58.6} & \multicolumn{2}{|c|}{53.5} & \multicolumn{2}{|c|}{$65.2 \%$} \\
\hline Socioeconomic status $(M=0)$ & 0.67 & $(1.59)$ & 0.34 & $(1.48)$ & -0.04 & $(1.31)$ & 0.18 & $(1.52)$ & -1.55 & $(1.41)$ \\
\hline No. of inhabitants $(M d n)$ & \multicolumn{2}{|c|}{$50.000-100.000$} & \multicolumn{2}{|c|}{$50.000-100.000$} & \multicolumn{2}{|c|}{$50.000-100.000$} & \multicolumn{2}{|c|}{$10.000-50.000$} & \multicolumn{2}{|c|}{$10.000-50.000$} \\
\hline
\end{tabular}

adopting products from all over the domain, the members of this category mainly adopt products from a specific technology cluster of products within the domain. The Appendix shows that these groups score disproportionally higher on ownership of certain products. Gadget cluster adopters have a relatively large ownership and purchase intention of small, portable consumer electronic products for personal use (e.g., gadgets), such as the iPod, MP3 player, mobile telephone with a camera, or a notebook. Household cluster adopters: household products have a relatively large ownership of products that can be used simultaneously by the entire household, such as a desktop computer, a DVD player, and to a lesser extent, a digital camera.
- Nonadopters are $14 \%$ of the sample; they own very few products and have low intention of purchasing any products.

Although these categories bear similarities to the categories identified by Rogers (2003), they provide additional insights by identifying cluster-specific adoption strategies.

Table 4 presents the descriptive statistics of all variables associated with actualized innovativeness over the categories. ANOVAs revealed highly significant differences for trendiness, $F=166.14, p<0.001$, opinion leadership, $F=181.66$, $p<0.001$, and ideas from the following information sources: 


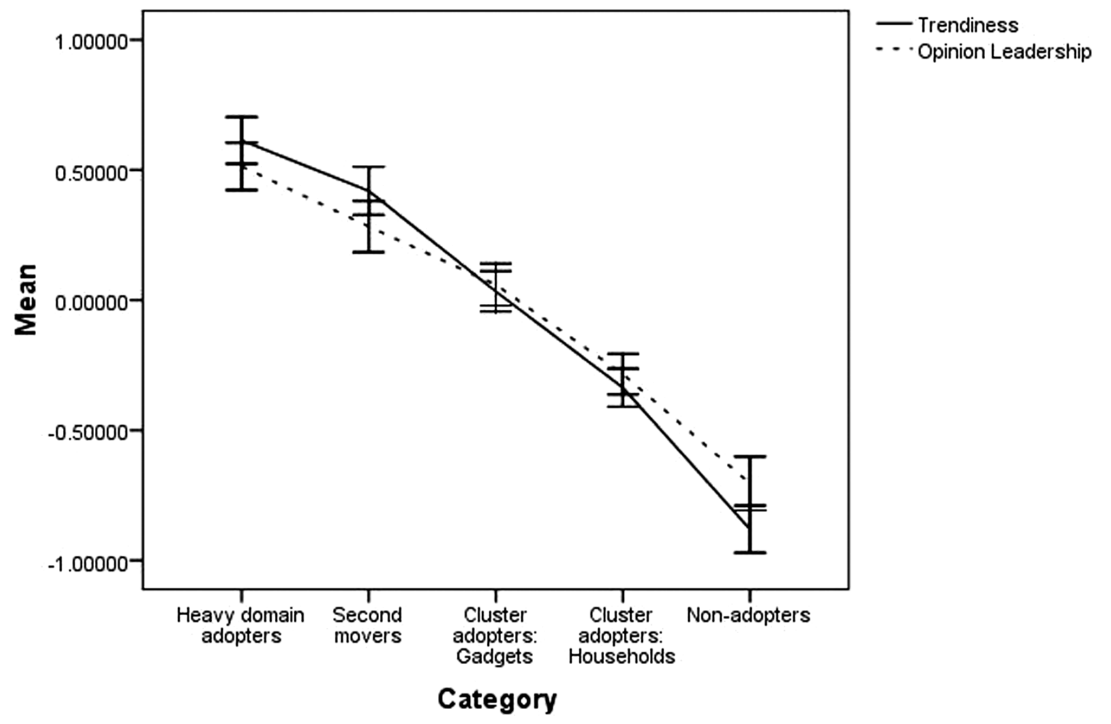

FIG. 2. Mean values and 95\% confidence intervals per category for trendiness and opinion leadership.

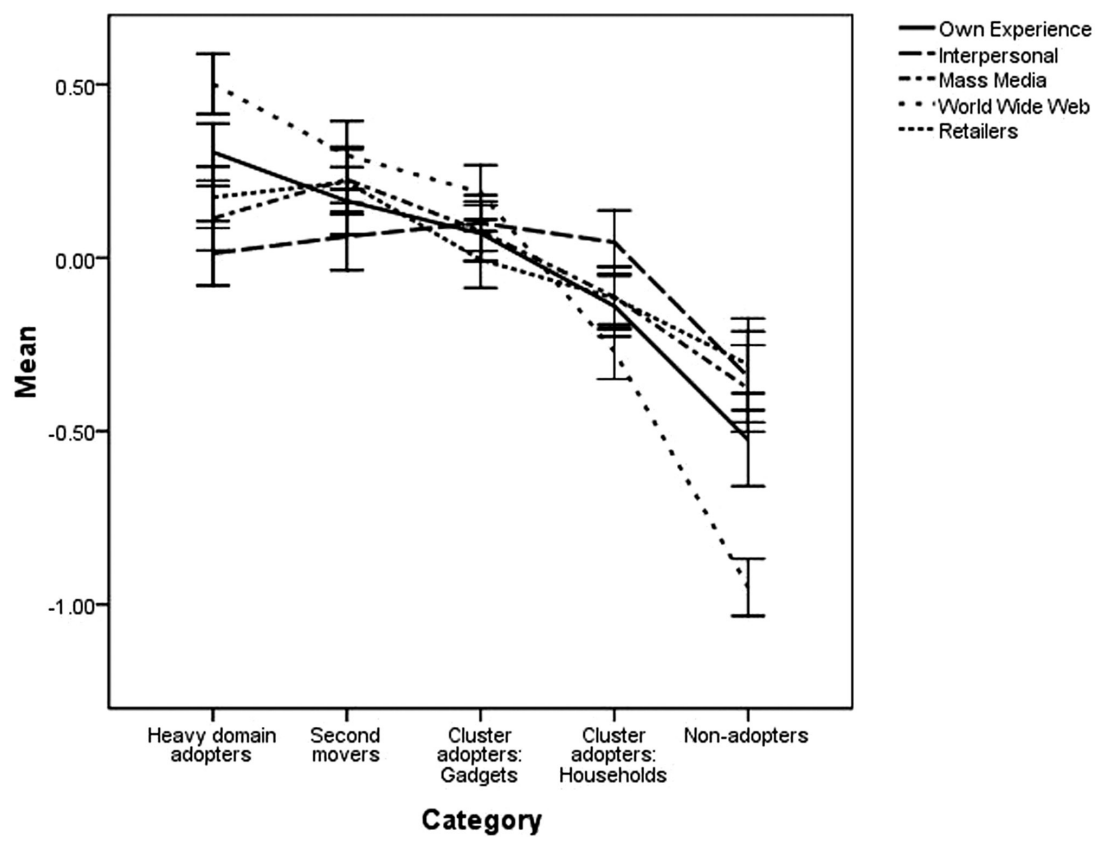

FIG. 3. Mean values and $95 \%$ confidence intervals per category for use of information source variables.

own experience, $F=37.80, p<0.001$, interpersonal sources, $F=10.61, p<0.001$, mass media, $F=19.14, p<0.001$, the WWW, $F=145.26, p<0.001$, and retailers, $F=15.96$, $p<0.001$.

Trendiness and opinion leadership are plotted against the categories in Figure 2; these two variables are strongly linearly related to the categories ordered by actualized innovativeness, which is in line with the findings of Van Rijnsoever and Donders (2009) (for trendiness) and Rogers (2003) (for opinion leadership). Figure 3 plots the use of informationsource variables against the five consumer categories. It is clear that among all information sources, the WWW is most strongly related to the categorization. The differences for interpersonal sources are the smallest and are purely caused by the nonadopters, who hardly use interpersonal sources. Without this category, there would be no significant difference in use of interpersonal sources. The other sources are weakly related. Note that there are no significant differences in use of information sources between the heavy domain adopters and the second movers, except for the use of own experience, $F=4.76, d f=1, p<0.05$, and the WWW, $F=9.49, d f=1, p<0.01$. Of the external information sources, the WWW is the main communication channel that differentiates these two categories. There are differences with regard to the cluster-specific adopter categories with regard to own experience, $F=11.81, d f=1$, $p<0.001$, mass media, $F=9.34, d f=1, p<0.01$, and most substantially, the WWW, $F=65.44, d f=1, p<0.001$. The 
TABLE 5. Multinomial logit model predicting group membership. ${ }^{\mathrm{a}}$

\begin{tabular}{|c|c|c|c|c|c|c|c|c|c|c|c|c|}
\hline & \multicolumn{3}{|c|}{ Heavy domain adopters } & \multicolumn{3}{|c|}{ Second movers } & \multicolumn{3}{|c|}{ Cluster adopters: Gadgets } & \multicolumn{3}{|c|}{ Cluster adopters: Households } \\
\hline & $B$ & Wald $\chi^{2}$ & $p$ & $B$ & Wald $\chi^{2}$ & $p$ & $B$ & Wald $\chi^{2}$ & $p$ & $B$ & Wald $\chi^{2}$ & $p$ \\
\hline Intercept & 2.99 & 33.63 & $* * *$ & 2.74 & 28.17 & $* * *$ & 2.08 & 16.86 & $* * *$ & 2.81 & 38.86 & $* * *$ \\
\hline Age (standardized) & -2.09 & 159.27 & $* * *$ & -2.20 & 174.61 & $* * *$ & -2.47 & 230.67 & $* * *$ & -1.00 & 52.08 & $* * *$ \\
\hline Gender (female: $n=2$ ) & -0.74 & 8.44 & $* *$ & -0.57 & 4.94 & $*$ & 0.01 & 0.00 & & -0.22 & 1.05 & \\
\hline Socioeconomic status & 0.84 & 94.17 & $* * *$ & 0.72 & 70.08 & $* * *$ & 0.60 & 51.86 & $* * *$ & 0.56 & 58.20 & $* * *$ \\
\hline Inhabitants & 0.10 & 0.91 & & 0.11 & 0.99 & & 0.16 & 2.39 & & 0.06 & 0.48 & \\
\hline Trendiness & 1.64 & 82.94 & $* * *$ & 1.49 & 68.27 & $* * *$ & 0.98 & 31.65 & $* * *$ & 0.72 & 21.76 & $* * *$ \\
\hline Opinion leadership & 0.05 & 0.09 & & -0.05 & 0.11 & & 0.05 & 0.09 & & -0.02 & 0.02 & \\
\hline Own experience & 0.10 & 0.73 & & 0.00 & 0.00 & & -0.02 & 0.02 & & 0.02 & 0.04 & \\
\hline Interpersonal sources & 0.34 & 8.62 & $* *$ & 0.28 & 5.74 & $*$ & 0.24 & 4.57 & $*$ & 0.28 & 9.11 & $* *$ \\
\hline Mass media & -0.24 & 3.21 & & -0.03 & 0.04 & & -0.08 & 0.41 & & -0.05 & 0.20 & \\
\hline World Wide Web & 0.99 & 38.54 & $* * *$ & 0.77 & 23.48 & $* * *$ & 0.85 & 30.03 & $* * *$ & 0.57 & 15.83 & $* * *$ \\
\hline Retailers & -0.10 & 0.66 & & -0.06 & 0.24 & & -0.23 & 3.71 & & -0.15 & 2.16 & \\
\hline$\%$ predicted correct & 51.64 & & & 4.02 & & & 56.77 & & & 63.67 & & \\
\hline Nagelkerke $R^{2}$ & & & & & & & 0.59 & & & & & \\
\hline
\end{tabular}

${ }^{\mathrm{a}}$ The overall percentage predicted correct is $51 \%$. Nonadopters are the reference category; percentage predicted correct for nonadopters is $74.83 \%$. $* p<0.05$. ** $p<0.01$. *** $p<0.001$.

findings are generally in line with those of Rogers (2003), who claimed that earlier adopters have more contact with interpersonal sources and mass media than do later adopters, but note that some effects are nonlinear among the ordered categories.

Significant cross-group differences exist with regard to sociodemographics. For example, age has a significant effect over all groups, $F=374.82, d f=4, p<0.001$. Heavy domain adopters are about the same age as second movers, $F=2.37, d f=1, p=0.12$, and gadget cluster adopters are the youngest group of all. Household cluster adopters and nonadopters are, in general, older consumers. The mean age of nonadopters is above retirement level, which explains their lack of interest in the product category.

Heavy domain adopters are overwhelmingly male, and second movers also are mostly male. This corresponds to a higher interest in the product category by males (Van Rijnsoever \& Donders, 2009). Note that gadget cluster adopters are mostly female. The gender balance for the household cluster adopters is roughly equal; this might be due to the fact that the products in this group also are mostly owned by the entire household. Nonadopters are mostly female, which also is in line with earlier findings (Leung \& Wei, 1999; Van Rijnsoever \& Donders, 2009).

Large differences exist in socioeconomic status (SES), $F=109.25, d f=4, p<0.001$. Heavy domain adopters have the highest SES, followed by second movers, who have a significantly lower SES, $F=8.82, d f=1, p<0.01$. SES of the former probably provides the resources to continue purchasing new products. The gadget cluster adopters have a slightly lower SES compared to the household adopter cluster, $F=5.79, d f=1, p<0.05$, which is probably due to the lower age of the former group. Nonadopters have the lowest SES, which provides an explanation for their lack of adopting products. Since the sample contained an overrepresentation of highly educated respondents, it is possible that the number of heavy domain adopters is overestimated by the clustering in comparison to the population.

The median number of inhabitants in the town of residence in the last two categories is slightly lower, but this difference is not significant across all groups.

Table 5 presents the multinomial logit model predicting category membership. With a pseudo $R^{2}$ of 0.59 , the model performs well. Overall, the model predicts $51 \%$ of the cases in the correct category. The model performs worst in predicting second movers (only 4.0\%), and best in predicting nonadopters $(74.8 \%)$. All other predicted percentages are above $50 \%$, which is a reasonable performance. Since the predictors used in the model are not used in the clustering procedure, the low hit rate for second movers does not indicate the quality of the cluster solution. Instead, the result means that the predicting variables in the model have little discriminatory value with regard to second movers compared to that of other categories; the reason for this is that the effects of the predictors for second movers are very similar to the effects of the predictors for heavy domain adopters and, to a lesser extent, similar to the effects for cluster adopters: gadgets. Further, the result means that purchase intentions, which are the main distinctive characteristics of second movers compared to the other categories, are not captured by the predictors in the model. Adding purchase intentions to the set of variables that are used as the basis for clustering has thus uncovered a new and interesting category of consumers that is difficult to characterize in terms of the selected sociodemographics, attitudes, and use of information sources.

\section{Conclusions}

The aim of this article was to extend consumer categorizations based on actualized innovativeness originally proposed by Rogers (2003). We proposed to explore categories of consumers on a domain-specific level, based on 
past adoption behavior and future purchase intensions and taking into account technology clustering among products. Five categories of consumers were identified: (a) heavy domain adopters, (b) second movers, (c), cluster-specific adopters: gadgets, (d) cluster-specific adopters: households, and (e) nonadopters. These categories possess many of the properties that also are attributed to the adopter categories by Rogers (2003), but the categories also discriminate consumers in terms of future purchase intentions and technology clusters.

As for intentions, our results show that purchase intention for existing products is highest among the second movers, although it is likely that the heavy domain adopters also will be the first ones to adopt new products as soon as they enter the market.

As for technology clusters, the market segments identified show that there is a difference between groups of consumers who adopt products from all over the product domain and groups of consumers who choose to adopt heavily from a single technology cluster within the domain. This pattern shows that the products in a domain are not interchangeable but that there are specific patterns of adoption on the technology cluster level that need to be taken into account.

Further, since these categories are the result of a modelbased clustering procedure instead of standard deviations from the mean actualized innovativeness, the boundaries between the categories are not established ex ante but are revealed ex post by the empirical analysis. This is a methodological improvement with respect to the method used by Rogers (2003).

This study has uncovered differences in categories in terms of several consumer characteristics that can be used by marketers to identify group members and to customize their communication strategies; however, the multinomial logit model demonstrated that a challenge remains to correctly identify and target second movers. This group is important in the innovation diffusion process since members follow directly the heavy domain adopters when adopting new products and also adopt products from the entire product domain. Further, this group expresses a high intention of adopting consumer electronics. Because of their broad interest and high purchase intentions, this group bears much potential as a target group for retailers.

Future research should test the validity of our proposed innovativeness-based categorization for predicting future purchases. Although we provided several reasons in the introduction as to why inclusion of within domain technology cluster patterns and purchase intentions would lead to an increase in predictive validity, the cross-sectional setting of our study did not allow for such a test. Longitudinal data that better take into account the product life cycle would help provide more information on this area. Second, our set of products was limited to those that were available on the market at the time of surveying. Products about to be launched were not included, which led to lower purchase intentions in the heavy domain adopter category. The main reason behind our choice was that products not yet launched or about to be launched represent a very special case and should be treated differently. In particular, information about future products may be available only in selected information channels and is likely to display a much higher level of uncertainty than for products already on the market. Further research could develop more complex research designs where future products could be taken into account along with available products.

Third, a challenge remains to find characteristics that discriminate the second mover category from the other groups. Since the second movers follow the heavy domain adopters, a promising avenue might be to use the position of the agent in a social network as an explanatory variable (see Valente, 1995). Future research could investigate how members of the five categories are related to each other in a social network.

Finally, our categorization is based on the domain of consumer electronics. This domain exemplifies the key challenges of high-tech product domains and offers an ideal research context for testing the role played by innovativeness and the existence of within-domain clusters. Future research should assess whether the categorization also applies to other multiple-product domains.

\section{References}

Ajzen, I. (2005). Attitudes, personality and behavior (2nd ed.). Berkshire, England: Open University Press.

Alexander, D.L., Lynch, J.G., \& Wang, Q. (2008). As time goes by: Do cold feet follow warm intentions for really new versus incrementally new products? Journal of Marketing Research, 45(3), 307-319.

Bacher, J., Wenzig, K., \& Vogler, M. (2004). SPSS TwoStep Cluster-A first evaluation. Paper presented at the Rc33 Sixth International Conference on Social Science Methodology, Amsterdam. Retrieved from http://www. opus.ub.uni-erlangen.de/opus/volltexte/2004/81/pdf/a_04-02.pdf

Blackwell, R.D., Miniard, P.W., \& Engel, J.F. (2001). Consumer behavior. Fort Worth, TX: Harcourt College.

CBS. (2007). Statline database. Retrieved from Centraal Bureau voor de Statistiek (Statistics Netherlands), http://statline.cbs.nl/statweb/

Donders, A.R.T., van der Heijden, G.J.M.G., Stijnen, T., \& Moons, K.G.M. (2006). Review: A gentle introduction to imputation of missing values. Journal of Clinical Epidemiology, 59(10), 1087-1091.

Dunlap, R.E., Van Liere, K.D., Mertig, A.G., \& Jones, R.E. (2000). Measuring endorsement of the new ecological paradigm: A revised NEP scale. Journal of Social Issues, 56(3), 425-442.

Flynn, L.R., Goldsmith, R.E., \& Eastman, J.K. (1996). Opinion leader and opinion seekers: Two new measurement scales. Journal of the Academy of Marketing Science, 24(2), 137-147.

Fraley, C., \& Raftery, A.E. (1998). How many clusters? Which clustering method? Answers via model-based cluster analysis. Computer Journal, 41(8), 578-588.

Goldsmith, R.E., Freiden, J.B., \& Eastman, J.K. (1995). The generality/specificity issue in consumer innovativeness research. Technovation, 15(10), 601-612.

Goldsmith, R.E., \& Hofacker, C.F. (1991). Measuring consumer innovativeness. Journal of the Academy of Marketing Science, 19(3), 209-221.

Haughton, D., Legrand, P., \& Woolford, S. (2009). Review of three latent class cluster analysis packages: Latent Gold, poLCA, and MCLUST. American Statistician, 63(1), 81-91.

Hoffmann, S., \& Soyez, K. (2010). A cognitive model to predict domainspecific consumer innovativeness. Journal of Business Research, 63(7), 778-785. doi: 10.1016/j.jbusres.2009.06.007

Jöreskog, K., \& Sörbom, D. (2006). LISREL (Version 8.80). Lincolnwood, IL: Scientific Software International. 
Katz, E.P., \& Lazarsfeld, P.F. (1964). Personal influence. New York: Free Press.

Kiel, G., \& Layton, R.A. (1981). Dimensions of consumer information seeking behavior. Journal of Marketing Research, 18(2), 233-239.

Larose, R., \& Hoag, A. (1996). Organizational adoptions of the internet and the clustering of innovations. Telematics and Informatics, 13, 49-61.

Leung, L., \& Wei, R. (1999). Who are the mobile phone have-nots? New Media \& Society, 1(2), 209-226.

Linzer, D.A., \& Lewis, J. (2010). poLCA: Polytomous variable latent class analysis. Software available at http://www.r-project.org/

Midgley, D.F., \& Dowling, G.R. (1978). Innovativeness: The concept and its measurement. Journal of Consumer Research, 4(4), 229-242.

Mittal, B., \& Lee, M.S. (1989). A causal model of consumer involvement. Journal of Economic Psychology, 10(3), 363-389.

Morwitz, V.G., \& Schmittlein, D. (1992). Using segmentation to improve sales forecasts based on purchase intent: Which "intenders" actually buy? Journal of Marketing Research, 29(4), 391-405.

Podsakoff, P.M., MacKenzie, S.B., Lee, J.Y., \& Podsakoff, N.P. (2003). Common method biases in behavioral research: A critical review of the literature and recommended remedies. Journal of Applied Psychology, 88(5), 879-903.

R Development Core Team. (2007). R: A language and environment for statistical computing. Vienna R Foundation for Statistical Computing.

Robertson, T.S. (1971). Innovative behavior and communication. New York, NY: Holt, Rinehart and Winston. Software available at: http://www.rproject.org/

Roehrich, G. (2004). Consumer innovativeness-Concepts and measurements. Journal of Business Research, 57(6), 671-677.

Rogers, E.M. (2003). Diffusion of innovations (5th ed.). New York: Free Press.

Rogers, E.M., \& Cartano, D.G. (1962). Methods of measuring opinion leadership. Public Opinion Quarterly, 26(3), 435-441.
Sheppard, B.H., Hartwick, J., \& Warshaw, P.R. (1988). The theory of reasoned action: A meta-analysis of past research with recommendations for modifications and future research. Journal of Consumer Research, 15(3), 325-343.

Taylor, S. (1995). Decomposition and crossover effects in the theory of planned behavior: A study of consumer adoption intentions. International Journal of Research in Marketing, 12(2), 137-155.

Valente, T.W. (1995). Network models of the diffusion of innovations Cresskill, NJ: Hampton Press.

Van Rijnsoever, F.J., \& Castaldi, C. (2009). Perceived technology clusters and ownership of related technologies: The case of consumer electronics. Journal of the American Society for Information Science and Technology, 60(2), 381-392.

Van Rijnsoever, F.J., \& Donders, A.R.T. (2009). The effect of innovativeness on different levels of technology adoption. Journal of the American Society for Information Science and Technology, 60(5), 984-996.

Van Rijnsoever, F.J., \& Oppewal, H. (2009). Successive early adoption of technology generations: The case of video players. Paper presented at the meeting of the Australian \& New Zealand Marketing Academy. Retrieved from http://www.duplication.net.au/ANZMAC09/ papers/ANZMAC2009-184.pdf

Vermunt, J.K., \& Magidson, J. (2002). Latent class cluster analysis. In J.A. Hagenaars \& A.L. McCutcheon (Eds.), Applied latent class analysis (pp. 89-106). Cambridge, England: Cambridge University.

Vishwanath, A. (2005). Impact of personality on technology adoption: An empirical model. Journal of the American Society for Information Science and Technology, 56(8), 803-811.

Vishwanath, A., \& Goldhaber, G.M. (2003). An examination of the factors contributing to adoption decisions among late-diffused technology products. New Media \& Society, 5(4), 547-572.

\section{Appendix}

TABLE A1. Detailed distribution of ownership and intention variables over consumer categories.

\begin{tabular}{|c|c|c|c|c|c|c|}
\hline Category no. & $\begin{array}{l}\text { Heavy domain } \\
\text { adopters } \\
426\end{array}$ & $\begin{array}{c}\text { Second movers } \\
348\end{array}$ & $\begin{array}{l}\text { Cluster adopters: } \\
\text { Gadgets } \\
502\end{array}$ & $\begin{array}{l}\text { Cluster adopters: } \\
\text { Households } \\
501\end{array}$ & $\begin{array}{c}\text { Nonadopters } \\
290\end{array}$ & $\begin{array}{l}\text { Total } \\
2,067\end{array}$ \\
\hline \multicolumn{7}{|l|}{ Mobile telephone } \\
\hline No, no intention & 3 & 3 & 5 & 33 & 115 & 159 \\
\hline No, but intends to purchase & 0 & 2 & 2 & 18 & 11 & 33 \\
\hline First purchase & 16 & 32 & 30 & 210 & 124 & 412 \\
\hline Replacement purchase & 407 & 311 & 465 & 240 & 40 & 1,463 \\
\hline \multicolumn{7}{|l|}{ DVD player } \\
\hline No, no intention & 11 & 27 & 88 & 27 & 159 & 312 \\
\hline No, but intends to purchase & 4 & 29 & 32 & 40 & 24 & 129 \\
\hline First purchase & 54 & 215 & 301 & 343 & 96 & 1,009 \\
\hline Replacement purchase & 357 & 77 & 81 & 91 & 11 & 617 \\
\hline \multicolumn{7}{|l|}{ Broadband Internet } \\
\hline No, no intention & 11 & 7 & 52 & 86 & 263 & 419 \\
\hline No, but intends to purchase & 11 & 26 & 35 & 36 & 8 & 116 \\
\hline First purchase & 126 & 225 & 271 & 307 & 19 & 948 \\
\hline Replacement purchase & 278 & 90 & 144 & 72 & 0 & 584 \\
\hline \multicolumn{7}{|l|}{ Desktop } \\
\hline No, no intention & 47 & 29 & 119 & 23 & 215 & 433 \\
\hline No, but intends to purchase & 14 & 17 & 14 & 14 & 16 & 75 \\
\hline First purchase & 9 & 66 & 121 & 129 & 43 & 368 \\
\hline Replacement purchase & 356 & 236 & 248 & 335 & 16 & 1,191 \\
\hline \multicolumn{7}{|l|}{ Digital camera } \\
\hline No, no intention & 40 & 39 & 141 & 101 & 250 & 571 \\
\hline No, but intends to purchase & 30 & 69 & 94 & 72 & 12 & 277 \\
\hline First purchase & 102 & 172 & 221 & 286 & 28 & 809 \\
\hline Replacement purchase & 254 & 68 & 46 & 42 & 0 & 410 \\
\hline
\end{tabular}


TABLE A1. (Continued)

\begin{tabular}{|c|c|c|c|c|c|c|}
\hline Category no. & $\begin{array}{l}\text { Heavy domain } \\
\text { adopters } \\
426\end{array}$ & $\begin{array}{c}\text { Second movers } \\
348\end{array}$ & $\begin{array}{l}\text { Cluster adopters: } \\
\text { Gadgets } \\
502\end{array}$ & $\begin{array}{l}\text { Cluster adopters: } \\
\text { Households } \\
501\end{array}$ & $\begin{array}{c}\text { Nonadopters } \\
290\end{array}$ & $\begin{array}{l}\text { Total } \\
2,067\end{array}$ \\
\hline \multicolumn{7}{|c|}{ Mobile telephone with camera function } \\
\hline No, no intention & 95 & 48 & 52 & 443 & 275 & 913 \\
\hline No, but intends to purchase & 21 & 45 & 54 & 31 & 4 & 155 \\
\hline First purchase & 76 & 145 & 231 & 26 & 11 & 489 \\
\hline Replacement purchase & 234 & 110 & 165 & 1 & 0 & 510 \\
\hline \multicolumn{7}{|l|}{ Dolby surround system } \\
\hline No, no intention & 62 & 46 & 324 & 280 & 267 & 979 \\
\hline No, but intends to purchase & 52 & 146 & 34 & 55 & 2 & 289 \\
\hline First purchase & 148 & 137 & 139 & 130 & 14 & 568 \\
\hline Replacement purchase & 164 & 19 & 5 & 36 & 7 & 231 \\
\hline \multicolumn{7}{|l|}{ Notebook or laptop } \\
\hline No, no intention & 92 & 95 & 223 & 381 & 260 & 1,051 \\
\hline No, but intends to purchase & 67 & 108 & 68 & 38 & 6 & 287 \\
\hline First purchase & 75 & 120 & 180 & 59 & 24 & 458 \\
\hline Replacement purchase & 192 & 25 & 31 & 23 & 0 & 271 \\
\hline \multicolumn{7}{|l|}{ Flat-panel TV } \\
\hline No, no intention & 110 & 34 & 401 & 305 & 253 & 1,103 \\
\hline No, but intends to purchase & 134 & 252 & 47 & 115 & 14 & 562 \\
\hline First purchase & 123 & 62 & 54 & 72 & 23 & 334 \\
\hline Replacement purchase & 59 & 0 & 0 & 9 & 0 & 68 \\
\hline \multicolumn{7}{|l|}{ MP3 player } \\
\hline No, no intention & 185 & 139 & 230 & 407 & 284 & 1,245 \\
\hline No, but intends to purchase & 10 & 47 & 30 & 30 & 0 & 117 \\
\hline First purchase & 83 & 123 & 177 & 60 & 6 & 449 \\
\hline Replacement purchase & 148 & 39 & 65 & 4 & 0 & 256 \\
\hline \multicolumn{7}{|l|}{ Webcam } \\
\hline No, no intention & 171 & 129 & 300 & 416 & 290 & 1,306 \\
\hline No, but intends to purchase & 9 & 62 & 24 & 12 & 0 & 107 \\
\hline First purchase & 135 & 128 & 161 & 60 & 0 & 484 \\
\hline Replacement purchase & 111 & 29 & 17 & 13 & 0 & 170 \\
\hline \multicolumn{7}{|l|}{ High-definition TV (HDTV) } \\
\hline No, no intention & 181 & 93 & 491 & 389 & 273 & 1,427 \\
\hline No, but intends to purchase & 122 & 209 & 0 & 65 & 9 & 405 \\
\hline First purchase & 90 & 38 & 8 & 42 & 8 & 186 \\
\hline Replacement purchase & 33 & 8 & 3 & 5 & 0 & 49 \\
\hline \multicolumn{7}{|l|}{ iPod } \\
\hline No, no intention & 260 & 176 & 280 & 485 & 290 & 1,491 \\
\hline No, but intends to purchase & 43 & 78 & 74 & 15 & 0 & 210 \\
\hline First purchase & 80 & 80 & 132 & 1 & 0 & 293 \\
\hline Replacement purchase & 43 & 14 & 16 & 0 & 0 & 73 \\
\hline \multicolumn{7}{|l|}{ Game console } \\
\hline No, no intention & 225 & 180 & 378 & 457 & 286 & 1,526 \\
\hline No, but intends to purchase & 19 & 35 & 6 & 4 & 0 & 64 \\
\hline First purchase & 43 & 79 & 70 & 25 & 3 & 220 \\
\hline Replacement purchase & 139 & 54 & 48 & 15 & 1 & 257 \\
\hline \multicolumn{7}{|l|}{ Personal digital assistant } \\
\hline No, no intention & 222 & 246 & 451 & 473 & 290 & 1,682 \\
\hline No, but intends to purchase & 61 & 59 & 18 & 12 & 0 & 150 \\
\hline First purchase & 73 & 43 & 33 & 14 & 0 & 163 \\
\hline Replacement purchase & 70 & 0 & 0 & 2 & 0 & 72 \\
\hline
\end{tabular}

